Revista Eletrônica de Educação do Curso de Pedagogia do Campus Avançado de Jataí da Universidade Federal de Goiás [Vol I - n.1 ] [jan/jul] [ 2005 ]

ISSN: $1807-9342$

\title{
TRABALHO E FLEXIBILIZAÇÃO
}

\section{Luciene Lima de Assis Pires (CEFET-GO./UNED-Jataí e UFG/CAJ - lucienepires@brturbo.com)}

\section{Resumo:}

No presente artigo, analisa-se o trabalho como uma categoria que, independente das diferentes significações que adquiriu [adquire] ao longo dos tempos, é atual, presente e, principalmente, não está superada. Apresenta-se aqui três momentos não distintos, ao contrário, interligados entre si. Num primeiro momento analisou-se a construção da categoria trabalho na visão de Marx. Em seguida, estabeleceu-se de que forma o trabalho se efetivou a partir do início do século XX, com a organicidade proposta pelo taylorismo e aplicada nas indústrias Ford, originando a estrutura empregada e difundida pela empresa - o fordismo, bem como as transformações postas a partir da década de 70 do século passado, implementadas pelo toyotismo. Num terceiro momento analisou-se o trabalho e as transformações salientadas anteriormente inserindo neste contexto as mudanças que se processam na educação em consonância com um modelo de sociedade que se quer construir, ou melhor, manter.

\begin{abstract}
In the present article, the work is analyzed as a category that, independent of the different meanings that acquired [acquires] throghout the times, is current, present end mainly, is not surpassed. It is presented here three not distinct moments, in contrast, linked between itself. At a first moment it was analyzed construction of the category work in the vision of Marx. After that, the structure employed and spread out by the company was established of that it forms the work if accomplished from the beginning of century XX, with organization proposal for taylorism and applied in the Ford industries, originating - the fordism, as well as the transformations placed from the decade of 70 of the passed century, implemented for the toyotism. At one third moment one previously analyzed the work and the pointed out transformations inserting in this context the changes that if they had processed in the education in accord with a model of society that if wants to construct, or better, to keep.
\end{abstract}

Word-Key: Work - Ecucation - Flexibilit.

\section{Trabalho: uma construção inicial}

Sinto muito, mas não pretendo ser um imperador. Não é esse o meu ofício. Não pretendo governar ou conquistar quem quer que seja. Gostaria de ajudar - se possível - judeus, o gentio... negros... brancos.

Charles Chaplin - O último discurso

Trabalho! Categoria historicamente construída, historicamente destruída, historicamente modificada mas também historicamente permanente. Trabalho comunitário, 
tinerarius

Peflectionis
Revista Eletrônica de Educação do Curso de Pedagogia do Campus Avançado de Jataí da Universidade Federal de Goiás [Vol I - n.1 ] [jan/jul] [ 2005 ]

ISSN: $1807-9342$

trabalho artesanal, trabalho fabril. Trabalho! Remunerado, assalariado, produtivo. Trabalho manual, intelectual, qualificado. Trabalho excedente, trabalho concreto, trabalho abstrato... Trabalho adjetivado. Trabalho modificado? São tantos os adjetivos... A adjetivação modifica ou não o substantivo?

Discorrer sobre a categoria trabalho neste início de século torna-se uma tarefa árdua visto que o que se tem presenciado é a defesa de que o trabalho, que se modifica ao longo dos anos, é hoje uma categoria secundária e/ou superada. No entanto, sabe-se que o termo trabalho adquire uma série de significações em diferentes campos das ciências sociais mas só alcança seu verdadeiro sentido e dimensão a partir de uma inter-relação das perspectivas e análises desses diversos campos e, independente das diferentes significações, a categoria é atual, presente e, principalmente, não está superada. Para ANTUNES (2002) "se é um grande equívoco imaginar o fim do trabalho na sociedade produtora de mercadorias, é entretanto imprescindível entender quais mutações e metamorfoses vêm ocorrendo no mundo contemporâneo, bem como quais são seus principais significados e suas mais importantes conseqüências" (p. 16).

No DICIONÁRIO de ciências sociais (1987, p. 1247), o termo trabalho tem significado geral - trabalho ou esforço, freqüentemente no sentido de lida penosa mas dele derivam várias aplicações, usos análogos e derivados na economia, na sociologia, na filosofia. $\mathrm{O}$ termo trabalho é encontrado nos escritos políticos desde cerca de 1800 e é usado em cinco sentidos: inicialmente correspondia apenas a labor; durante o segundo quartel do século XIX, passa a ser usado como figura de linguagem, personificando um ato, em expressões como o valor do trabalho, o produto do trabalho; em 1888 o termo aparece definido no New English Dictionary como o organismo que congrega trabalhadores e operários e, neste sentido, trabalho indica a classe trabalhadora; a partir de 1906 o termo trabalho passa a ter uma quarta acepção, quando, na Grã-Bretanha, os membros da Câmara de Comuns passaram a intitular-se Partido Trabalhista; em outros países o termo adquiriu um quinto significado ligando-se aos trabalhadores da ala esquerda. (Idem, p. 1248).

O trabalho nas sociedades estratificadas, se comparado ao das comunidades primitivas, se diferencia mas a conotação - ou conotações - que se mantém ao longo dos séculos se liga a uma sociedade dividida, hierarquizada. No que se refere às sociedades antigas, tanto as orientais que se caracterizavam basicamente pela servidão voluntária, como as clássicas pelo Modo de Produção Escravista, bem como nas sociedades estamentais da Idade Média, os estudos 
sobre trabalho não adquiriram a importância que se faz presente na sociedade capitalista. É a partir do século XV, já na Idade Moderna - européia - que o trabalho se transforma efetivamente em objeto de estudo. As transformações econômicas, políticas, sociais, científicas, religiosas, territoriais, que se processam nas sociedades modernas, desencadeiam um novo modo de pensar e questões, até então adormecidas pelo poder da Igreja, passam a ser desveladas.

Este período é assim um marco na história do trabalho. Como outros marcos presentes na história da humanidade, passível de questionamentos mas aqui, tomar-se-á este marco como importante na construção teórica desta categoria e das novas relações que se estabelecem entre os indivíduos no processo de produção, a partir dele.

Sabe-se que as transformações que se processaram na produção agrícola européia no século XVIII impulsionaram o crescimento populacional do século seguinte.

\begin{abstract}
A mudança agrícola tinha precedido a Revolução Industrial e tornou possíveis os primeiros estágios de rápidos aumentos populacionais, e o ímpeto naturalmente continuou, embora as atividades agrícolas britânicas tivessem sofrido pesadamente com a queda que se seguiu aos preços anormalmente altos das guerras napoleônicas [...] o vasto aumento na produção, que capacitou as atividades agrícolas britânicas na década de 1830 a fornecer $98 \%$ dos cereais consumidos por uma população duas a três vezes maior que a de meados do século XVIII, foi obtido pela adoção geral de métodos descobertos no início do século XVIII, pela racionalização e pela expansão da área cultivada (HOBSBAWM, 1991, p. 65).
\end{abstract}

No entanto, afirma Hobsbawm, tudo isso, por sua vez, foi obtido pela transformação social e não tecnológica quais sejam, dentre outras, eliminação da cultura de subsistência e de velhas atitudes não comerciais em relação à terra. Este processo fez surgir na Grã-Bretanha "alguns grandes proprietários, um número moderado de arrendatários comerciais e um grande número de trabalhadores contratados" (Idem). Essa transformação foi um sucesso em termos de produtividade econômica mas seus efeitos sociais foram catastróficos o que era, no entanto, desejável do ponto de vista da industrialização "pois uma economia industrial necessita de mãode-obra, e de onde mais poderia vir esta mão-de-obra senão do antigo setor não industrial? [...] Os homens tinham que ser atraídos para as novas ocupações, ou - como era mais provável forçados a elas, pois inicialmente estiveram imunes a essas atrações ou relutantes em abandonar seu modo de vida tradicional." (Idem, p. 66)

A modificação na estrutura de produção e, conseqüentemente, na estrutura / formação da mão-de-obra passa a ser uma preocupação das novas categorias mandatárias. "Conseguir um número suficiente de trabalhadores era uma coisa: outra coisa era conseguir um número 
suficiente de trabalhadores com as necessárias qualificações e habilidades. A experiência do século XX tem demonstrado que este problema é tão crucial e mais difícil de resolver do que o outro" (HOBSBAWM, 1991, p. 66-67).

Desta forma, mão-de-obra qualificada, formação do trabalhador, preparação para o trabalho, passaram a ser expressões vinculadas diretamente à categoria trabalho e, neste sentido, ao se propor um estudo sobre trabalho e educação, escolas técnicas, universidades tecnológicas, o caminho a ser trilhado deve ser, inicialmente, a compreensão desta categoria.

Sabe-se que, conforme indica ANTUNES (2000) não há uma tendência generalizante e uníssona, quando se pensa no mundo do trabalho. Há, isso sim, diz ele, "uma processualidade contraditória e multiforme. Complexificou-se, fragmentou-se e heterogeneizou-se ainda mais a classe-que-vive-do-trabalho".

Neste sentido, neste trabalho optou-se por três momentos não distintos, ao contrário, concatenados entre si. Num primeiro momento analisa-se a construção da categoria trabalho na visão de Marx. Em seguida, estabeleceu-se de que forma o trabalho se efetivou a partir do início do século XX, com a organicidade proposta pelo taylorismo e aplicada nas indústrias Ford, originando a estrutura empregada e difundida pela empresa - o fordismo, bem como as transformações postas a partir da década de 70 do século passado, implementadas pelo toyotismo. Num terceiro momento analisa-se o trabalho e as transformações salientadas anteriormente inserindo neste contexto as mudanças que se processam na educação em consonância com um modelo de sociedade que se quer construir, ou melhor, manter.

\title{
2. Buscando raízes
}

\begin{abstract}
Neste mesmo instante a minha voz chega a milhões de pessoas pelo mundo afora ... milhões de desesperados, homens, mulheres, criancinhas... vítimas de um sistema que tortura seres humanos e encarcera inocentes. Aos que me podem ouvir eu digo: "Não desespereis!" A desgraça que tem caído sobre nós não é mais do que o produto da cobiça em agonia ... da amargura de homens que temem o avanço do progresso humano. Os homens que odeiam desaparecerão, os ditadores sucumbem e o poder que do povo arrebataram há de retornar ao povo. E assim, enquanto morrem os homens, a liberdade nunca perecerá.
\end{abstract}

Charles Chaplin - O último discurso

O trabalho torna o homem rude. Esta é uma expressão bastante difundida, presente no senso comum. E pouco se houve de que o trabalho torna o homem, homem. Ou que é pelo 
trabalho que o homem transforma a natureza e se transforma, produz e produz-se, simultaneamente. Compreender o homem como produtor de mercadoria e conseqüentemente produtor de si mesmo é compreender sua ação na natureza. "Ao atuar, sobre a Natureza externa a ele e ao modificá-la, ele modifica ao mesmo tempo sua própria natureza" (MARX, 1985, p. 149).

GORENDER (1995), apresentando uma das publicações de $O$ capital no Brasil, afirma que "acentua-se a ação transformadora do meio geográfico pelo homem de tal maneira que as condições geográficas se humanizam, à medida que se tornam prolongamentos do próprio homem" (p. XXI). Segundo ele, está em Marx a relação do homem com a natureza por meio do trabalho e a humanização sob o aspecto de autocriação do homem no processo de transformação da natureza pelo trabalho. "As mudanças nas formas de trabalho constituem os indicadores básicos da mudança das relações de produção e das formas sociais em geral do intercurso humano. O trabalho é, portanto, o fundamento antropológico das relações econômicas e sociais em geral" (Idem). Neste sentido a análise que Marx faz do trabalho na sociedade capitalista servirá de fundamento para a construção a ser aqui desenvolvida.

Para Marx, o homem conquistou liberdade em relação a natureza. Esta, determina aos animais o comportamento necessário para garantirem sua sobrevivência. $\mathrm{O}$ que ocorre com o homem é um processo diferente visto que, por meio do trabalho, encontrou formas de dominar a natureza, não mais se submetendo a ela. No entanto, os animais também trabalham e produzem mas num esquema diferenciado visto que os animais agem instintivamente e, só o homem é capaz de projetar a atividade antes de sua realização. "No fim do processo de trabalho obtém-se um resultado que já no início deste existiu na imaginação do trabalhador, e portanto idealmente" (MARX, 1985, p. 149). E é porque o trabalho dos homens é diferente do trabalho dos animais que pode-se afirmar que o homem modifica a natureza de acordo com suas possibilidades. Para Marx,

Antes de tudo, o trabalho é um processo entre o homem e a Natureza, um processo em que o homem, por sua própria ação, media, regula e controla seu metabolismo com a Natureza. Ele mesmo se defronta com a matéria natural como uma força natural. Ele põe em movimento as forças naturais pertencentes à sua corporalidade, braços e pernas, cabeça e mão, a fim de apropriar-se da matéria natural numa forma útil para sua própria vida (Idem).

Segundo Marx, o trabalhador é, na verdade um capital vivo o que é, para ele, uma infelicidade. Como capital vivo tem portanto necessidades e, "em cada momento em que não trabalha perde os 
tinerarius

Peflectionis
Revista Eletrônica de Educação do Curso de Pedagogia do Campus Avançado de Jataí da Universidade Federal de Goiás [Vol I - n.1 ] [jan/jul] [ 2005 ]

ISSN: $1807-9342$

seus juros, e por conseguinte, a existência. [...] Ele produz-se a si mesmo, e o homem enquanto trabalhador, enquanto mercadoria, constitui o produto de todo o processo" (MARX, 1993, p. 173). O trabalhador, diz ele, só existe como trabalhador a partir do momento em que existe como capital para si mesmo, e só existe como capital, quando há um capital para ele. “A existência do capital é a sua existência, a sua vida, já que este, independente dele, determina o conteúdo da sua vida" (Idem, p. 174).

Sendo assim, para Marx, "a produção não produz unicamente o homem como uma mercadoria, a mercadoria humana, o homem sob a forma de mercadoria; de acordo com tal situação, produzi-lo ainda como um ser espiritual e fisicamente desumanizado...” (Idem). O trabalho não pertence exclusivamente ao homem.

Marx pressupunha o trabalho numa forma a que pertencesse exclusivamente ao homem mas não é o que ocorre. Na sociedade capitalista a utilização da força de trabalho pelo homem é o próprio trabalho. "Por força de trabalho ou capacidade de trabalho entendemos o conjunto das faculdades físicas e espirituais que existem na corporalidade, na personalidade viva de um homem e que ele põe em movimento toda vez que produz valores de uso de qualquer espécie" (1985, p. 139). E quando a força de trabalho é colocada a disposição de um comprador no mercado, transforma-se em mercadoria. "O estado em que o trabalhador se apresenta no mercado como vendedor de sua própria força de trabalho deixou para o fundo dos tempos primitivos o estado em que o trabalho humano não se desfez ainda de sua primeira forma instintiva" (Idem, p. 149).

Para Marx, a existência do trabalhador encontra-se reduzida às mesmas condições que a existência de qualquer outra mercadoria. "O trabalhador tornou-se uma mercadoria e terá muita sorte se puder encontrar um comprador. E a procura, de que depende a vida do trabalhador, é determinada pelo capricho dos ricos e dos capitalistas" (MARX, 1993, p. 102). O trabalhador, diz ele, nada pode criar sem a natureza, sem o mundo externo sensível. Este é o material onde se realiza o trabalho, onde ele é ativo, a partir do qual e por meio do qual produz coisas. (Idem, p. $160)$.

O processo do trabalho, processo de produção de mercadorias, é um processo histórico de produção de valor. Ao desenvolver uma atividade o homem transforma o objeto de seu trabalho, cria produto criando também valor. "Seu produto é um valor de uso; uma matéria natural adaptada às necessidades humanas mediante transformação de forma. $\mathrm{O}$ trabalho uniu 
itinerarius

Peflectionis
Revista Eletrônica de Educação do Curso de Pedagogia do Campus Avançado de Jataí da Universidade Federal de Goiás [Vol I - n.1 ] [jan/jul] [ 2005 ]

ISSN: $1807-9342$

com seu objetivo. O trabalho está objetivado e o objeto trabalhado" (MARX, 1985, p.151).

Ao se afirmar que o produto da atividade do homem é uma matéria adaptada às necessidades humanas poderia a priori se dizer que o homem produz então apenas para suprir suas necessidades, o que não é incorreto. No entanto, as necessidades humanas são, também elas, produzidas, criando-se um ciclo de produção/satisfação que é, para Marx, egoísta. Cada homem, diz ele, "especula sobre a maneira como criar no outro uma nova necessidade para o forçar a novo sacrifício, o colocar em nova dependência, para o atrair a uma nova espécie de prazer e, deste modo, à ruína. Cada qual procura estabelecer sobre os outros um poder estranho, de maneira a encontrar assim a satisfação da própria necessidade egoísta" (MARX, 1993, p. 207). Desta forma, a produção na sociedade capitalista é também produção de necessidades sociais que são historicamente condicionadas.

O homem, tem necessidades básicas, biológicas, que se transformam em necessidades sociais e são também supridas socialmente. Ele precisa, devido a sua natureza biológica, de se alimentar mas o seu alimento bem como a necessidade dele, são produzidos socialmente. As necessidades humanas e o trabalho que vão supri-las, têm sentido social. O trabalho, diz Marx (1993), "parece ainda ter um sentido social, um significado de genuína vida comunitária, ainda não chegou à indiferença em relação ao seu conteúdo e à plena existência para si mesmo, isto é, à abstração de todos os outros seres" (p. 176).

Esta questão social é, entretanto, despercebida pela economia política. Segundo Marx, a economia política considera o trabalho abstratamente como uma coisa. O trabalho é uma mercadoria, diz ele, e como tal se submete às oscilações do mercado como qualquer outra mercadoria. "Se o preço é elevado, a procura é grande e se o preço é baixo a oferta é grande. Como sucede com as outras mercadorias. O preço do trabalho deve diminuir; é em parte a concorrência entre o capitalista e o trabalhador, em parte a concorrência entre os próprios trabalhadores que provoca esta descida" (MARX, 1993, p. 115-116).

Compreendendo desta forma, o preço do trabalho não é definido pelo trabalhador e não é também estável. Como não é estável permite o acúmulo de capital isto porque, segundo Marx, o capital é trabalho acumulado. Esta é outra relação estabelecida por Marx ao afirmar que "no trabalho, todas as diferenças naturais, culturais e sociais da atividade individual aparecem e são remuneradas de modo diverso, enquanto o capital inerte mantém um rendimento invariável e é indiferente à atividade individual real" (MARX, 1993, p. 103). Para ele o trabalhador não tem 
apenas de lutar pelos meios físicos de subsistência; deve ainda lutar para alcançar trabalho, ou seja, deve lutar pela possibilidade e pelos meios de realizar a sua atividade (Idem).

O processo de acúmulo de capital desenvolve, dialetalmente, um processo de divisão do trabalho. Sabe-se que "a acumulação do capital aumenta a divisão do trabalho e a divisão do trabalho aumenta o número de trabalhadores; reciprocamente, o número crescente de trabalhadores incrementa a divisão do trabalho e a divisão crescente do trabalho intensifica a acumulação do capital” (MARX, 1993, p. 104-105).

\begin{abstract}
Como resultado da divisão do trabalho, por um lado, e da acumulação do capital, por outro, o trabalhador torna-se mesmo mais completamente dependente do trabalho e de um tipo de trabalho particular, extremamente unilateral, mecânico. Por conseqüência, assim como ele se vê reduzido espiritual e fisicamente à condição de uma máquina e se transforma de ser humano em simples atividade abstrata e em bandulho, também assim se torna progressivamente dependente de todas as flutuações do preço corrente, no emprego do capital e dos caprichos do rico (Idem).
\end{abstract}

Neste processo, nova relação se põe: a separação do capital, da propriedade e do trabalho. Para o trabalhador, segundo Marx, a separação do capital, da renda da terra e do trabalho é fatal. Por conseguinte, diz ele, "para os trabalhadores é que a separação do capital, da propriedade de raiz e do trabalho constitui uma separação inelutável, vital e perniciosa. O capital e a propriedade de raiz não precisam persistir nesta abstração, mas sim o trabalho do operário" (Idem, p. 101).

O que se tem na verdade, é a formação de um ciclo vicioso que beneficia o empregador em detrimento do trabalhador. Segundo Marx, a subida dos salários desperta no trabalhador o mesmo desejo de enriquecimento que no capitalista, mas só ocorre no segundo. No caso do trabalhador só o pode satisfazer pelo sacrifício do seu corpo e espírito visto que os salários são controlados pela própria estrutura econômica. Para ele, "o aumento dos salários pressupõe e provoca a acumulação do capital; assim ele aliena progressivamente o produto do trabalho do trabalhador. De igual modo, a divisão do trabalho torna-o cada vez mais unilateral e dependente, e introduz não só a concorrência de outros homens, mas também das máquinas. Visto que o trabalhador foi reduzido à máquina, a máquina pode com ele competir" (MARX, 1993, p. 106).

Para analisar sobre a acumulação de capital em detrimento do trabalhador, o que desencadeia um processo de expropriação do trabalho, Marx fundamenta-se em estudos de economistas, dentre eles, Adam Smith. Segundo Adam Smith apud Marx (1993), originalmente todo o produto do trabalho pertence ao trabalhador. Mas imediatamente acrescenta, diz Marx, 
Ztinerarius

Teflectionis
Revista Eletrônica de Educação do Curso de Pedagogia do Campus Avançado de Jataí da Universidade Federal de Goiás [Vol I - n.1 ] [jan/jul] [ 2005 ]

ISSN: $1807-9342$

“que, na realidade, o trabalhador recebe apenas a parte mínima e absolutamente indispensável do produto; precisamente tanto quanto necessita para existir como trabalhador, não como homem, e para gerar a classe escravizada dos trabalhadores, não a humanidade" (p. 107). Na visão dos economistas, o homem só poderia aumentar o valor dos produtos naturais por meio do trabalho, unicamente através do trabalho. O trabalho constitui a propriedade ativa do homem e é o único preço imutável das coisas. No entanto, diz Marx, nada é mais fortuito nem está sujeito a maiores flutuações do que o preço do trabalho.

Embora a divisão do trabalho aumente o poder produtivo do trabalho e a riqueza e o requinte da sociedade, empobrece o trabalhador e transforma-o em máquina. [...] Torna o trabalhador cada vez mais dependente do capitalista, expõe-no a maior concorrência e arrasta-o para a corrida da superprodução seguida pela correspondente crise econômica (MARX, 1993, p. 108).

Na visão de Marx, o trabalho em si, em qualquer condição, ou seja, universalmente, não é benéfico e esta conclusão, para ele, pode ser tirada da própria análise dos economistas. "Na medida em que sua finalidade se resume ao aumento da riqueza, é pernicioso e deletério, e que semelhante conclusão se tira do próprio argumento do economista, se bem que ele não lhe preste atenção" (MARX, 1993, p.108).

O processo de trabalho da forma como Marx o apresenta, é uma atividade orientada a um fim, para produzir valores de uso, "apropriação do natural para satisfazer a necessidades humanas, condição universal do metabolismo entre o homem e a Natureza, condição natural eterna da vida humana e, portanto, independente de qualquer forma dessa vida, sendo antes comum a todas as suas formas sociais" (MARX, 1985, p. 153). Sabe-se que o trabalhador não detém o produto de seu trabalho da mesma forma que não detém sua própria força de trabalho, força de trabalho esta que é, como dito anteriormente, o trabalho em si. Na sociedade capitalista dividida, estratificada, as relações que se desenvolvem entre trabalhadores e proprietários são relações de dependência. Mas desenvolve-se também, no interior da classe trabalhadora, uma hierarquia assegurada e mantida pela divisão do trabalho.

Esta divisão do trabalho não se desvincula ao contrário, interfere na estrutura de produção e, à medida que ela se expande, tende a levar a uma maior dependência e empobrecimento do trabalhador. Para Marx (1993), quando a divisão do trabalho se expande, “torna-se necessário, para que um mesmo número de operários tenha emprego permanente, que antes se tenham acumulado igual provisão de gêneros alimentícios e uma provisão de materiais, 
instrumentos e utensílios, provisão muito maior do que teria sido necessária num estado de coisas menos avançado" (p. 135).

Mas esta não é a única conseqüência da divisão do trabalho apontada por Marx, para ele,

a divisão do trabalho é a expressão econômica do caráter social do trabalho no interior da alienação. Ou então, uma vez que o trabalho constitui apenas uma expressão da atividade humana no seio da alienação, da manifestação da vida enquanto alienação da vida, a divisão do trabalho não passa do estabelecimento alienado da atividade humana como atividade genérica rela ou como atividade do homem enquanto ser genérico (Idem, p. 220).

Para Marx "o produto do trabalho é o trabalho que se fixou num objeto, que se transformou em coisa física, é a objetivação do trabalho. A realização do trabalho constitui simultaneamente a sua objetivação" (1993, p. 151). O grande fundamento do debate de Marx com a questão do trabalho é o diálogo que ele estabelece com Hegel. Em Hegel o trabalho é objetivação e, neste sentido é exteriorização do sujeito na realidade do objeto e, na exteriorização deste objeto para a construção do sujeito.

O objeto é destruído como objeto externo para se constituir em objeto para o sujeito e não mais objeto fora do sujeito. Neste sentido sujeito e objeto se constituem. Nesta relação haveria, num primeiro momento, um aleamento, uma exteriorização, momento esse, necessário para que a consciência do sujeito se efetive. Neste processo a consciência e o objeto se constituem, sempre mediados pelo trabalho. Para Hegel, objetivação e trabalho são semelhantes, se correspondem. Isto seria positivo pois permitira que a consciência, ao se objetivar no trabalho, se efetivasse.

No entanto, Marx critica Hegel dizendo que este só analisou os aspectos positivos do trabalho. Isto porque o indivíduo se põe no trabalho mas não se reconhece nele. A objetivação não leva ao reconhecimento leva sim, ao estranhamento pois o trabalhador, ao ser expropriado do objeto, se distancia dele. Vale ressaltar que esta não é uma condição ontológica do trabalho. A condição ontológica do trabalho é a objetivação e a alienação, é uma condição histórica. $\mathrm{O}$ capitalismo é uma particularidade histórica e, como particularidade histórica, o reconhecimento do sujeito é negado. Para Marx o indivíduo se põe no objeto mas não se reconhece nele porque o objeto não the pertence.

O trabalhador põe a sua vida no objeto; porém, agora ela já não lhe pertence a ele, mas 
ao objeto. [...] A alienação do trabalhador no seu produto significa não só que o trabalho se transforma em objeto, assume uma existência externa, mas que existe independentemente, fora dele e a ele estranho, e se torna um poder autônomo em oposição com ele; que a vida que deu ao objeto se torna uma força hostil e antagônica (MARX, 1993, p. 160).

Para Marx a condição ontológica do trabalho não desaparece mas fica subsumida na condição histórica. "O trabalhador torna-se servo do objeto; pelo fato de receber um objeto de trabalho, isto é, de receber trabalho; em seguida, pelo fato de receber meios de subsistência. Deste modo, o objeto capacita-o para existir, primeiramente como trabalhador, em seguida como sujeito físico" (idem). O resultado de tal servidão é que o trabalhador só pode manter-se como sujeito físico enquanto trabalhador e só é trabalhador enquanto sujeito físico.

A alienação não se revela apenas no resultado, mas também no processo da produção, no interior da própria atividade produtiva e a economia política, segundo Marx, esconde a alienação na natureza do trabalho porque não examina a imediata relação entre o trabalhador (trabalho) e a produção. O trabalho não é voluntário, é trabalho imposto, forçado e como tal não constitui a satisfação de uma necessidade, mas apenas um meio de satisfazer outras necessidades, como dito anteriormente. "Chega-se à conclusão de que o homem (o trabalhador) só se sente livremente ativo nas suas funções animais - comer, beber e procriar, quando muito, na habitação, no adorno, etc. - enquanto nas funções humanas se vê reduzido a animal. O elemento animal torna-se humano e o humano animal" (MARX, 1993, p. 162).

Para Marx é também na alienação que se encontra o segredo da propriedade privada. Segundo ele, o capital só se constitui como tal pela mediação da força de trabalho que é propriedade do trabalhador. Mas o trabalhador não é proprietário, há, na sociedade capitalista, uma complexa estrutura fundiária que interfere nas relações de trabalho.

\footnotetext{
Os costumes, o caráter, etc., diferem de propriedade para propriedade e parecem estar de harmonia com o tipo de território, ao passo que mais tarde só a bolsa do homem, e já não o seu caráter ou individualidade, se relaciona com a propriedade fundiária. [...] É inevitável [...] que a relação entre o proprietário e o trabalhador se reduza à relação econômica de explorador e explorado; que toda a relação pessoal entre o proprietário e a sua propriedade se extinga, transformando-se em simples riqueza material; o casamento do interesse juntamente com o homem, se rebaixe a objeto de especulação (MARX, 1993, p. 151)
}

O trabalho, que segundo Marx tem também um sentido social, um significado próprio na vida comunitária, como salientado anteriormente, é dependente da estrutura da propriedade privada, do capital mobilizado. 


\begin{abstract}
O proprietário fundiário realça a nobre linhagem da sua propriedade, as recordações e reminiscências feudais, a poesia da lembrança, a sua natureza entusiástica, a sua importância política, etc., e, ao falar em termos econômicos, afirma que só a agricultura é produtiva. Ao mesmo tempo, pinta o seu adversário como um indivíduo velhaco, regateador, trapaceiro, fraudulento, avaro, mercenário, rebelde, sem coração e sem alma, alienado da comunidade e sempre pronto a negociá-la, usuário, mesquinho, gerando, alimentando e acariciando a concorrência e com ela a pobreza, o crime e a dissolução de todos os laços sociais, sem honra, sem princípios, sem poesia, sem substância e tudo o mais. (MARX, 1993, p. 177-178)
\end{abstract}

Tem-se então que se pressupor a abolição positiva da propriedade privada, "o homem produz o homem e se produz a si mesmo e aos outros homens; como objeto que constitui a atividade direta da sua personalidade, é ao mesmo tempo a sua existência para si” (Idem, p. 194). Se, para Marx, a essência subjetiva da propriedade privada, a propriedade privada enquanto atividade para si própria, como sujeito, como pessoa, é o trabalho, fica claro porque, para ele, a economia política não considerava a propriedade privada como simples condição externa ao homem, e “já não julgava se poderia considerar ao mesmo tempo como um produto da energia real e do movimento da propriedade privada, como um movimento da indústria moderna e uma força que acelerou e intensificou o dinamismo e o desenvolvimento da indústria, até fazer um poder da consciência" (MARX, 1993, p.183).

Neste movimento da indústria numa sociedade produtora de mercadorias, as relações de trabalho se estabelecem assim de forma dinâmica mas internamente desenrolam-se profundas mudanças que caracterizam diferentes momentos de crise. Analisando a crise que se desenvolve no final do século XX, Antunes (2002) afirma que "a lógica do sistema produtor de mercadorias vem convertendo a concorrência e a busca da produtividade num processo destrutivo que tem gerado uma imensa precarização do trabalho e aumento monumental do exército industrial de reserva, do número de desempregados" (p. 16).

Para ele, "a crise experimentada pelo capital, bem como suas respostas, das quais o neoliberalismo e a reestruturação produtiva da era da acumulação flexível são expressão, têm acarretado, entre tantas outras conseqüências, profundas mudanças no interior do mundo do trabalho" (Idem, p. 15).

Ocorre assim o que Antunes chama de inversão da lógica societal. Consolidam-se mediações que ele denomina de mediações de segunda ordem "que passaram a se constituir como elemento fundante do sistema de metabolismo social do capital. Desprovido de uma orientação 
itinerarius Teflectionis
Revista Eletrônica de Educação do Curso de Pedagogia do Campus Avançado de Jataí da Universidade Federal de Goiás [Vol I - n.1] [jan/jul] [ 2005 ]

ISSN: $1807-9342$

humanamente significativa, o capital assume, em seu processo, uma lógica onde o valor de uso das coisas foi subordinado ao seu valor de troca" (2002, p. 17).

Pode se afirmar assim, que são crescentes os exemplos de países excluídos do movimento de reposição dos capitais produtivos e financeiros e do padrão tecnológico necessário, o que acarreta repercussões profundas no interior desses países, particularmente no que diz respeito ao desemprego e à precarização da força humana de trabalho (ANTUNES, 2002, p. 33).

Estas questões desencadearam, desde meados do século passado, um processo de reestruturação na produção que é mister seja analisado. Segundo Antunes (2002), "em meio a tanta destruição de forças produtivas, da natureza e do meio ambiente, há também, em escala mundial, uma ação destrutiva contra a força humana de trabalho, que tem enormes contingentes precarizados ou mesmo à margem do processo produtivo, elevando a intensidade dos níveis de desemprego estrutural" (p. 33).

Para ele, mesmo com o significativo avanço tecnológico encontrado nas sociedades atuais, o que levaria a se pressupor a possibilidade, em escala mundial, de uma redução da jornada ou do tempo de trabalho, o que se tem presenciado é o inverso: ampliação das jornadas de trabalho, citando como exemplo Itália e Japão. O modelo de organização racional do trabalho desenvolvido nas empresas e que desencadeia uma estrutura de produção capitalista desde o século passado, é o que analisaremos a seguir. Esta é uma análise presentificada, necessária, mediata.

\section{Trabalho e formação: uma organização (i) racional}

\footnotetext{
Os ditadores liberam-se, porém escravizam o povo. Lutemos agora para libertar o mundo, abater as fronteiras nacionais, dar fim à ganância, ao ódio e à prepotência. Lutemos por um mundo de razão, um mundo em que a ciência e o progresso conduzam à ventura de todos nós.

Charles Chaplin - O último discurso
}

Na sociedade capitalista, globalizada, neoliberal, competitiva, polivalente, é preciso compreender as relações de trabalho vinculadas a dois símbolos da produção capitalista: o fordismo / taylorismo e o toyotismo. A estrutura de produção no início do século passado encontrava-se abalada pelas relações conturbadas desencadeadas, dentre outros aspectos, pela Primeira Guerra Mundial - e pós-guerra -, pela Revolução Russa. A resposta ao período de crise 
tinerarius

- Peflectionis
Revista Eletrônica de Educação do Curso de Pedagogia do Campus Avançado de Jataí da Universidade Federal de Goiás [Vol I - n.1 ] [jan/jul] [ 2005 ]

leva ao desenvolvimento de um processo de organização racional do trabalho tendo como um de seus expoentes Frederick Taylor que, já em 1911, publicou Princípios de administração científica, propondo o incentivo ao uso de maquinarias, produto da união entre capital e ciência que se traduz na ciência aplicada; o emprego de menores nas linhas de produção com economia de salários e redução do poder de articulação dos trabalhadores adultos; e práticas de subcontratação que utilizavam um trabalhador qualificado, difundindo assim, novos mecanismos de controle do trabalho / trabalhador.

A organização proposta por Taylor ganha força nas mãos de Henry Ford, ao ser implantada na indústria automobilística. Embora o modelo fordista seja normalmente associado a uma evolução nos princípios e práticas tayloristas, a forma como cada um deles se apropria, interpreta e atua junto ao meio ambiente circundante pode apresentar diferenças. Buscou-se no modelo fordista, alterar e construir um meio ambiente que lhe fosse favorável e que permitisse a realização de um determinado projeto econômico. $\mathrm{O}$ fordismo não se limitou apenas aos espaços produtivos, buscou-se construir novas relações, novos padrões de consumo e de valores sociais que pudessem dar sustentação a uma determinada forma de produção. A reestruturação iniciada nas indústrias Ford leva ao surgimento de um modelo de organização de trabalho no Estados Unidos. "No geral, pode-se dizer que o americanismo e o fordismo derivam da necessidade imanente de organizar uma economia pragmática e que os diversos problemas examinados deveriam ser os elos da cadeia que assinalam a passagem do velho individualismo econômico para a economia programática" (GRAMSCI, 1988, p. 375).

Segundo Gramsci, estes problemas surgem em virtude das diversas formas de resistência ao processo de desenvolvimento e no embate de uma determinada força social. As forças subalternas que deveriam ser manipuladas e racionalizadas de acordo com os novos objetivos, resistiram, diz ele. Mas, acrescenta: "também resistem alguns setores das forças dominantes, ou pelo menos aliados das forças dominantes. O proibicionismo, que nos Estados Unidos era uma condição necessária para aperfeiçoar o novo tipo de trabalhador conforme à uma indústria fordizada, caiu em virtude da oposição de forças marginais, ainda atrasadas, e não em virtude da oposição dos industriais ou operários, etc." (Idem, p. 376).

O americanismo, na sua forma mais acabada, exige, segundo Gramsci, uma condição preliminar, "da qual os americanos que trataram destes problemas jamais se ocuparam". Para ele, existe na América o que ele chama de uma composição demográfica racional, ou seja, não 
existem classes numerosas sem uma função essencial no mundo da produção, classes parasitárias, diz ele. Isto facilitou a expansão dos novos elementos que estavam sendo postos na organização do trabalho.

Na Europa, a tradição de classes criadas pela riqueza e a complexidade da história passada, diz ele, deixou o que ele chamou de sedimentações passivas: categorias ligadas a diferentes áreas - comércio, agricultura, clero, intelectuais - saturadas e fossilizadas. Isto, aliado às tradições históricas e culturais não permitiu, como ocorreu na América, uma base sadia para o desenvolvimento da indústria e do comércio, nos moldes do americanismo. "Na América, a racionalização determinou a necessidade de elaborar um novo tipo humano, conforme ao novo tipo de trabalho e de produção" (Idem, p. 382).

A elaboração deste novo homem estaria assim definida e defendida pelos elementos econômicos ou, como disse Gramsci, da política econômica. Para ele,

\begin{abstract}
A americanização exige um determinado ambiente, uma determinada estrutura social (ou vontade decidida de criá-la) e um determinado tipo de Estado. O Estado é o Estado Liberal, não no sentido do liberalismo alfandegário ou da efetiva liberdade política, mas no sentido mais fundamental da livre iniciativa e do individualismo econômico que alcança através de meios próprios, como 'sociedade civil', através do próprio desenvolvimento histórico, o regime da concentração industrial e do monopólio (GRAMSCI, 1988, p. 388).
\end{abstract}

O desencadear de novos processos produtivos, exigiu uma produção mais flexível.

"Novos processos de trabalho emergem, onde o cronômetro e a produção em série e de massa são 'substituídos' pela flexibilização da produção, pela 'especialização flexível', por novos padrões de busca de produtividade, por novas formas de adequação da produção à lógica do mercado" (ANTUNES, 2000, p. 24).

O modelo de produção que se estruturou no início do século passado na indústria automobilística americana, calcado fundamentalmente no modelo de produção das indústrias Ford, era assim, fundamentalmente,

a forma pela qual a indústria e o processo de trabalho consolidaram-se ao longo deste século, cujos elementos constitutivos básicos eram dados pela produção em massa, através da linha de montagem e de produtos mais homogêneos; através do controle dos tempos e movimentos pelo cronômetro taylorista e da produção em série fordista; pela existência do trabalho parcelar e pela fragmentação das funções; pela separação entre elaboração e execução no processo de trabalho; pela existência de unidades fabris concentradas e verticalizadas e pela constituição/consolidação do operário-massa, do trabalhador coletivo fabril, entre outras dimensões. Menos do que um modelo de 

[Vol I - n.1 ] [jan/jul] [ 2005 ]

ISSN: $1807-9342$

organização societal, que abrangeria igualmente esferas ampliadas da sociedade, compreendemos o fordismo como o processo de trabalho que, junto com o taylorismo, predominou na grande indústria capitalista ao longo deste século (ANTUNES, 2000, p. 25).

Neste início de século, o Estado Liberal não foi superado. As políticas neoliberais mantêm a essência da mesma estrutura liberal. A organização racional do trabalho, do início do século passado, ganha, porém novos contornos em uma sociedade na qual o avanço tecnológico delineia novas relações para uma mesma estrutura. Analisando as mudanças ocorridas no mundo do trabalho, Antunes (2000) afirma que "em uma década de grande salto tecnológico, a automação, a robótica e a microeletrônica invadiram o universo fabril, inserindo-se e desenvolvendo-se nas relações de trabalho e de produção do capital" (p. 23).

O que se tem observado no que Antunes chama de 'universo do mundo do trabalho' no capitalismo contemporâneo é uma múltipla processualidade, diz ele. "De um lado verificou-se uma desproletarização do trabalho industrial, fabril, nos países do capitalismo avançado, com maior ou menor repercussão em áreas industrializadas do Terceiro Mundo. Em outras palavras, houve uma diminuição da classe operária industrial tradicional” (ANTUNES, 2000, p. 49).

Para ele, o efeito dessas transformações é brutal. E o mais sério deles, sem precedentes na era moderna, é a expansão do desemprego estrutural, que atinge o mundo em escala global. "Pode-se dizer, de maneira sintética, que há uma processualidade contraditória que, de um lado, reduz o operariado industrial e fabril; de outro, aumenta o subproletariado, o trabalho precário e o assalariamento no setor de serviços" (ANTUNES, 2000, p. 49-50).

O modelo americano não foi de todo superado mas a crise do fordismo não representa algo novo, é uma das diferentes manifestações da crise permanente do capitalismo e que, por volta da década de 70 do século passado, teve como manifestação novas mudanças no mundo do trabalho preconizadas desta vez pela indústria japonesa.

O toyotismo, como ficou conhecido este novo movimento pode ser considerado como um estágio superior de racionalização do trabalho mas que não rompeu com a lógica do taylorismo-fordismo. Há inclusive autores que o denominam neofordismo. Entretanto, no campo da gestão da força de trabalho, o toyotismo realiza um salto qualitativo na captura da subjetividade operária pela lógica do capital, o que o distingue, pelo menos no plano da consciência de classe, do taylorismo-fordismo.

No toyotismo, ao contrário do fordismo, diz Antunes, "a produção é voltada e 
conduzida diretamente pela demanda. A produção é variada, diversificada e pronta para suprir o consumo. É este quem determina o que será produzido, e não o contrário, como se procede na produção em série e de massa do fordismo" (ANTUNES, 2000, p. 35). Outro ponto essencial do toyotismo, segundo Antunes, é que:

\begin{abstract}
para a efetiva flexibilização do aparato produtivo, é também imprescindível a flexibilização dos trabalhadores. Direitos flexíveis, de modo a dispor desta força de trabalho em função direta das necessidades do mercado consumidor. O toyotismo estrutura-se a partir de um número mínimo de trabalhadores, ampliando-os, através de horas extras, trabalhadores temporários ou subcontratação, dependendo das condições de mercado (Idem, p. 36).
\end{abstract}

É oportuno ressaltar que com o toyotismo não se tem apenas a flexibilização do processo produtivo. A flexibilização do processo pressupõe também um produto flexível.

Segundo Antunes, "para atender às exigências mais individualizadas de mercado, no melhor tempo e com melhor 'qualidade', é preciso que a produção se sustente num processo de produção flexível, que permita a um operário operar com várias máquinas (em média cinco máquinas, na Toyota), rompendo-se com a relação um homem/uma máquina que fundamenta o fordismo" (ANTUNES, 2000, p. 34).

O toyotismo é uma resposta à crise do fordismo dos anos 70. Ao invés do trabalho desqualificado, o operário torna-se polivalente. Ao invés da linha individualizada, o trabalhador se integra em uma equipe. "Com o toyotismo, parece desaparecer o trabalho repetitivo, ultrasimples, desmotivante e embrutecedor. Finalmente, estamos na fase do enriquecimento das tarefas, da satisfação do consumidor, do controle de qualidade" (GOUNET, 1991, p. 43 apud ANTUNES, 2000, p. 37).

Pode-se afirmar que o fordismo e o toyotismo são seqüência de uma mesma lógica. Não te trata apenas de flexibilizar o processo produtivo é preciso também a flexibilização da organização do trabalho, diz Antunes. Para ele, "deve haver agilidade na adaptação do maquinário e dos instrumentos para que novos produtos sejam elaborados. Neste ponto encontrase mais uma nítida diferença frente à rigidez do fordismo" (ANTUNES, 2000, p. 35).

Flexibilizar a organização do trabalho é flexibilizar também o próprio trabalhador. É entender a formação humana, como diz Frigotto (2000b), "no contexto da reestruturação produtiva e globalização excludente, da dramática crise estrutural do trabalho assalariado que produz esterilização de vidas e, portanto, das novas formas de alienação do trabalho" (p. 25-26). 
É, por outro lado, acrescenta ele, "entendê-la também, dentro dos limites ambientais e políticos do desenvolvimento industrial do tipo fordista e pós-fordista e das relações assimétricas de poder existentes a nível global" (Idem).

Para Frigotto, o modelo de regulamentação fordista transcendeu o âmbito puramente econômico. Há um corpo conceitual da teoria do capital humano. Trata-se de um corpo teórico, diz ele, mais sofisticado do que a perspectiva psicologista da teoria da modernização. "A teoria do capital humano passou por um intenso debate interno, particularmente na década de 60 e 70, e, ao mesmo tempo, teve amplo uso político e ideológico na definição de macropolíticas educacionais orientadas pelos organismos internacionais e regionais" (2000b, p. 37).

Paulatina e insistentemente passou-se a ouvir o novo 'coro'. Ao processo de globalização e de reestruturação produtiva, sob uma nova base científica e tecnológica estão os países não desenvolvidos - que preferem ser denominados de países em desenvolvimento. Estes, “dependem da educação básica, de formação profissional, qualificação, requalificação. Todavia, não é de qualquer educação e formação" (Idem, p. 45). Que educação e formação são essas? Questiona Frigotto.

Segundo ele, "trata-se de uma educação e formação que desenvolvam habilidades básicas no plano do conhecimento, das atitudes e dos valores, produzindo competências para gestão de qualidade, para a produtividade e competitividade e, conseqüentemente, para a "empregabilidade"” (Idem).

No bojo deste processo tem-se assim o trabalho subordinado ao capital e a formação subordinada ao trabalho visto que as novas tecnologias de base microeletrônica e informática vêm agregando novos elementos à formação de trabalhador.

\title{
4. Mundo do trabalho e formação do trabalhador: o mesmo lado de uma mesma moeda
}

\begin{abstract}
A cobiça envenenou a alma do homem... Levantou no mundo as muralhas do ódio... e tem-nos feito marchar a passo de ganso para a miséria e os morticínios. Criamos a época da velocidade, mas nos sentimos enclausurados dentro dela. A máquina, que produz abundância, tem-nos deixado em penúria. Nossos conhecimentos fizeram-nos céticos; nossa inteligência, empedernidos e cruéis. Pensamos em demasia e sentimos bem pouco. Mais do que máquinas, precisamos de humanidade.Mais do que de inteligência, precisamos de afeição e doçura. Sem essas duas virtudes, a vida será de violência e tudo será perdido.
\end{abstract}


Dentre os autores que analisam a questão da formação humana cabe aqui ressaltar Frigotto, que tem colocado novos aportes neste debate. Para ele, a educação deve ser entendida como prática social, constitutiva e constituinte das relações sociais. Ela é assim, um campo social de disputa hegemônica e deve ser apreendida no plano das determinações e relações sociais (2000).

Segundo Frigotto, na perspectiva das classes dominantes a educação, historicamente, tem se voltado para habilitar técnica, social e ideologicamente para o trabalho. "O caráter subordinado das práticas educativas aos interesses do capital historicamente toma formas e conteúdos diversos, no capitalismo nascente, no capitalismo monopolista e no capitalismo transnacional ou na economia globalizada" (FRIGOTTO, 2000, p. 32). A função social da educação subordina-se desta forma, às demandas do mercado.

\footnotetext{
No plano histórico mais distante, o inventário das posições entre os fundadores do liberalismo clássico e entre os iluministas sinaliza como a questão da educação na perspectiva da subordinação das relações capitalistas é, ao mesmo tempo, necessária e problemática. Há, de um lado, a necessidade de que a reprodução da força de trabalho seja moldada, forjada, fabricada para a disciplina e subordinação das novas relações de produção (FRIGOTTO, 2000, p. 33).
}

Os debates sobre a formação do trabalhador, aptidões, salário, mão-de-obra, já estavam postos desde Marx. Segundo ele,

\begin{abstract}
Pode ser que se argumente que as profissões exigindo aptidões específicas ou maior instrução se tornaram de maneira geral mais remuneradas, enquanto os salários pela atividade mecânica, uniforme, que qualquer um pode aprender depressa e com facilidade, baixaram e têm necessariamente de baixar como resultado da maior concorrência. E é precisamente este tipo de trabalho que, no atual estado de organização do trabalho, é o mais comum (MARX, 1993, p. 110).
\end{abstract}

$\mathrm{Na}$ sociedade atual, ao se transferir para o trabalhador a responsabilidade de seu processo educativo se está, em verdade, transferindo também para ele a culpa pelo desemprego. Sabe-se que na situação de desemprego estrutural, o Exército Industrial de Reserva é uma contingência necessária. De todo modo o que se divulga - na mídia, por exemplo -, é que há oferta de vagas no mercado, mas não há trabalhadores qualificados para assumi-las.

A esta tendência acrescenta-se outra que se refere à criação de coordenadores técnicos encarregados de manterem as instalações automatizadas em funcionamento, presente 
também desde o século passado. Segundo Antunes, paralelamente a esta tendência de especialização do trabalhador, acrescenta-se outra,

\begin{abstract}
dada pela desqualificação de inúmeros setores operários, atingidos por uma gama diversa de transformações que levaram, de um lado, à desespecialização do operário industrial oriundo do fordismo e, por outro lado, à massa de trabalhadores que oscila entre os temporários (que não têm nenhuma garantia no emprego), aos parciais (integrados precariamente às empresas), aos subcontratados, terceirizados (embora se saiba que há também terceirização em segmentos ultraqualificados), aos trabalhadores da "economia informal", enfim, a este enorme contingente que chega até a faixa de $50 \%$ da população (ANTUNES, 2000, p. 60)
\end{abstract}

Antunes(1992b, p. 41), citando CORIAT, afirma - no que se refere à desespecialização dos operários profissionais, em decorrência da criação dos 'trabalhadores multifuncionais' introduzidos pelo toyotismo - que é importante ressaltar que esse processo também significou um ataque ao saber profissional dos operários qualificados, com o fim de diminuir seu poder sobre a produção e aumentar a intensidade do trabalho (apud ANTUNES, 2000, p. 61). Segundo ele, constata-se, por um lado, um efetivo processo de intelectualização do trabalho manual. De outro, e em sentido radicalmente inverso, uma desqualificação e mesmo subproletarização intensificadas, presentes no trabalho precário, informal, temporário, parcial, sub-contratado, etc. (ANTUNES, 2000, p. 62).

Acreditava-se que uma melhor qualificação do trabalhador levaria a uma resistência deste trabalhador ao avanço do capitalismo, entretanto, contraditoriamente, tem-se presenciado um processo inverso, segundo Antunes,

\begin{abstract}
aqueles segmentos mais qualificados, mais intelectualizados, que se desenvolveram junto com o avanço tecnológico, pelo papel central que exercem no processo de criação de valores de troca, poderiam estar dotados, ao menos objetivamente, de maior potencialidade anticapitalista. Mas contraditoriamente, esses setores mais qualificados são exatamente aqueles que têm vivenciado, subjetivamente, maior envolvimento "integracionista" por parte do capital, da qual a tentativa de manipulação elaborada pelo toyotismo é a melhor expressão, ou têm sido responsáveis, muitas vezes, por ações que se pautam por concepções de inspiração neocorporativa (ANTUNES, 2000, p. 97).
\end{abstract}

O reordenamento político e econômico vivenciado atualmente, em escala mundial, tem trazido um colorido diferente para a educação brasileira, reflexo do caleidoscópio composto pelas políticas neoliberais difundidas / asseguradas pelos organismos internacionais. A política presente na república de professores ${ }^{1}$ coroou os diferentes níveis da educação escolar brasileira

\footnotetext{
${ }^{1}$ Denominação dada por Hélgio Trindade ao livro no qual discute as políticas públicas - neoliberais - para o ensino superior no governo de Fernando H. Cardoso. TRINDADE (1999).
} 
tinerarius

Peflectionis
Revista Eletrônica de Educação do Curso de Pedagogia do Campus Avançado de Jataí da Universidade Federal de Goiás [Vol I - n.1 ] [jan/jul] [ 2005 ]

com medidas reformistas forçando a adesão a elas. No que se refere ao ensino profissionalizante, por exemplo, a proposta de mudança abrangeria todos os níveis mas, basicamente, o nível médio e as escolas técnicas federais, foram afetados. A possibilidade de formação mais rápida, via cursos tecnológicos, veio atender às necessidades postas / criadas pelo mercado, de uma formação flexível para um mercado também flexível.

Neste contexto se insere a cefetização das escolas técnicas federais. Estas escolas, que sempre foram consideradas centros de referência na formação de profissionais, inserem-se com bastante ênfase neste novo modelo: formação mais rápida, diversificada, em consonância com o mercado de trabalho, e com os interesses do capital e das políticas neoliberais, mas nem sempre em consonância com a identidade da instituição.

Diz-se que o Brasil precisa se inserir no modelo de formação flexível presente nos países considerados desenvolvidos. Diz-se sobre o fim da história. Diz-se que a formação do trabalhador deve adequar-se às novas exigências do mercado. Diz-se que a centralidade do trabalho não mais é referência neste mundo pós-moderno. Diz-se não haver mais classes fundamentais.

Sendo verdadeiras estas afirmações poder-se-ia afirmar também que a crise vivida pela sociedade capitalista pressuporia ainda o fim da racionalidade. $\mathrm{Na}$ verdade isto não de dá. Mesmo compreendendo que no fordismo, por exemplo, a máquina era vista como prolongamento da mão humana e que hoje ela incorpora também um prolongamento do cérebro humano, aquela não substitui este. Questionar se categorias como trabalho, razão, história, estão superadas não é o básico. É preciso saber antes se as condições históricas que deram origem a elas ainda estão postas. E a resposta é afirmativa.

O canto da sereia é eficaz e os Ulisses, não conseguindo manter a resistência, vão sendo cooptados. A cada ano novas músicas são entoadas, e as instituições, ao contrário do que se poderia supor, soltam rapidamente as amarras e abrem os ouvidos ao novo canto, inserindo-se nesta estrutura mediata, totalizante, presentificada, histórica, do Modo de Produção Capitalista. No entanto não se pode ignorar que é justamente esta historicidade que possibilita os questionamentos. É desta historicidade que resultam as classes fundamentais não superadas. É esta historicidade que os pós-modernistas tentam ocultar e que, na verdade, salienta o caráter violento e destrutivo do próprio capitalismo. 


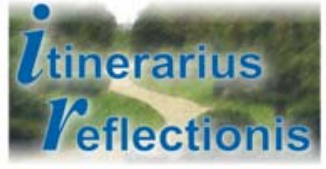

\begin{abstract}
Revista Eletrônica de Educação do Curso de Pedagogia do Campus Avançado de Jataí da Universidade Federal de Goiás [Vol I - n.1] [jan/jul] [ 2005 ]
\end{abstract}

ISSN: $1807-9342$

A dificuldade de configurar empiricamente, no capitalismo atual, tanto a classe detentora do capital quanto o coletivo que constituiu a classe trabalhadora, não elide sua existência enquanto uma relação entre forças antagônicas inconciliáveis. $O$ aparente desaparecimento das classes sociais fundamentais que a literatura conservadora expressa sob a noção de sociedade pós-industrial, ou sociedade do conhecimento, ou as análises vinculadas ao pós-modernismo, encobre seu caráter violento e destrutivo, sem precedentes. (FRIGOTTO, 2001, p. 42).

A barbárie se reproduz e é por isso que se pode afirmar que a adjetivação não modifica a essência do sujeito. A adjetivação do trabalho não o exclui como categoria presente na sociedade atual.

\title{
Referências bibliográficas
}

ADORNO, Theodor W. Educação e emancipação. Tradução de Wolfgang Leo Maar. Rio de Janeiro: Paz e Terra, 1995.

ANTUNES, Ricardo. Adeus ao trabalho? Ensaio sobre as metamorfoses e a centralidade do mundo do trabalho. 7. ed. rev. ampl. São Paulo: Cortez; Campinas, SP: Editora da Universidade Estadual de Campinas, 2000.

. Reestruturação produtiva e mudanças no mundo do trabalho numa ordem neoliberal.

In.: Dourado, Luiz F. Paro, Vitor Henrique (Orgs.) Políticas públicas e educação básica. São Paulo: Xamã, 2001, p.13-27.

Os sentidos do trabalho: ensaio sobre a afirmação e a negação do trabalho. 6. ed. São Paulo: Boitempo, 2002.

DICIONÁRIO de ciências sociais / Fundação Getúlio Vargas, Instituto de Documentação; Benedicto Silva, coordenação geral; Antônio Garcia de Miranda Netto.../et. al./ 2. ed. Rio de Janeiro: Editora da Fundação Getúlio Vargas, 1987.

FRIGOTTO, Gaudêncio. A educação e a crise do capitalismo real. 4. ed. São Paulo: Cortez, 2000.

Educação, crise do trabalho assalariado e do desenvolvimento: teorias em conflito. In.: FRIGOTTO, Gaudêncio (Org.). Educação e crise do trabalho: perspectivas de final de século. 4. ed. Petrópolis, RJ: Vozes, 2000b, p.25-54. (Coleção estudos culturais em educação)

A nova e a velha faces da crise do capital e o labirinto dos referenciais teóricos. In.: FRIGOTTO, Gaudêncio e CIAVATTA Maria (Orgs.). Teoria e educação no labirinto do capital. Petrópolis, RJ: Vozes, 2001, p.21-46.

GORENDER, Jacob. Apresentação. In.: MARX, Karl. O capital: crítica da economia política. Apresentação de Jacob Gorender; coordenação e revisão de Paul Singer; tradução de Régis Barbosa e Flávio R. Kothe. 2. ed. São Paulo: Nova Cultural, 1985. (Os economistas, vol.I), p. VII-LXXII.

GRAMSCI, Antônio. Maquiavel, a política e o Estado moderno. Tradução de Luiz Mário Gazzeneo. 6. ed. Rio de Janeiro: Civilização Brasileira, 1988. 
Revista Eletrônica de Educação do Curso de Pedagogia do Campus Avançado de Jataí da Universidade Federal de Goiás [Vol I - n.1 ] [jan/jul] [ 2005 ]

ISSN: $1807-9342$

HOBSBAWM, Eric J. A era das revoluções: 1789 - 1848. Trad. Maria Tereza Lopes Teixeira e Marcos Penchel. 8.ed. Rio de Janeiro: Paz e Terra, 1991.

MARX, Karl. O capital: crítica da economia política. Apresentação de Jacob Gorender; coordenação e revisão de Paul Singer; tradução de Régis Barbosa e Flávio R. Kothe. 2. ed. São Paulo: Nova Cultural, 1985. (Os economistas, vol.I)

Manuscritos econômico-filosófico. Textos filosóficos. Tradução de Artur Morão. Lisboa: Edições 70, 1993. 